\title{
Analysis of the Outer Contour Characteristics of Roadway Forming under the Influence of Cutting Head Vibration
}

\author{
Zhixiang Liu $\left(\mathbb{D},{ }^{1}\right.$ Shuai Wang $\mathbb{D},{ }^{1}$ Miao Xie $\mathbb{D},{ }^{1}$ and Chunxue Xie $\mathbb{D}^{2}$ \\ ${ }^{1}$ Research Institute of Mineral Resources Development and Utilization Technology and Equipment, \\ Liaoning University of Engineering and Technology, Fuxin, Liaoning Province 123000, China \\ ${ }^{2}$ School of Mechanics and Engineering, Liaoning University of Engineering and Technology, Fuxin, \\ Liaoning Province 123000, China \\ Correspondence should be addressed to Chunxue Xie; xcxlntu@126.com
}

Received 28 December 2020; Accepted 4 May 2021; Published 25 May 2021

Academic Editor: Antonio Batista

Copyright (C) 2021 Zhixiang Liu et al. This is an open access article distributed under the Creative Commons Attribution License, which permits unrestricted use, distribution, and reproduction in any medium, provided the original work is properly cited.

\begin{abstract}
Considering that the trajectory of the cutting head of the longitudinal axis roadheader directly affects the surface morphology of the roadway, the formation mechanism of the outer profile of the roadway obtained by the cutting head is analyzed, and the dynamic model of the cutting part was constructed. The variation law of the vibration swing angle of the cutting head under different working conditions was obtained, and the coordinate of the cutting head of the roadheader in the roadway space coordinate system was determined by using the robot kinematics analysis method. The mathematical model of cutting the outer outline of the roadway by the cutting head is constructed. Through the numerical calculation and analysis, the characteristics of the formed outer profile of the roadway were analyzed considering the influence of the vibration of the cutting head. The results show that the difference between the "pit" and the "peak ridge" obtained by considering the vibration of the cutting head is larger than that without considering the vibration of the cutting head, which shows that the outer outline of the roadway obtained by the real cutting is more rougher than that without considering the vibration of the cutting head. With the increase of the cutting lifting angle, the maximum and average value of the difference between the "pit" and the uplift "peak ridge" on the coal and rock shows an increasing trend, and with the increase of the cylinder pressure, the maximum values of the horizontal swing angle "pit" and the uplift "peak ridge" gradually increase. The vibration of the cutting head when cutting coal and rock will have a great influence on the outer profile of the roadway, which cannot be ignored in the research of accurate autonomous cutting control algorithm of roadheader. The research results of this paper can provide a basis for the optimization of cutting parameters and high-precision forming control method of roadheader.
\end{abstract}

\section{Introduction}

The longitudinal shaft roadheader is the mainstream fully mechanized roadheader in coal mine at present, and the movement track of its cutting head directly affects the surface topography of the roadway. The study shows that the surface roughness of roadway will affect the propagation characteristics of electromagnetic wave of wireless communication in the coal mine. The propagation loss increases with the increase of roughness, and the greater the propagation frequency of electromagnetic wave is, the more serious the influence of roadway surface roughness is [1]. The surface roughness of the roadway has a great influence on the main part of the confined attached turbulent jet. With the increase of the roughness, the axial velocity of the main section decreases faster, the thickness of the low wind speed area increases, and the eddy current zone is easy to be formed in the recirculation area. With the increase of roughness inhomogeneity, the eddy current area in the roadway increases gradually [2]. The surface roughness of the roadway will affect the contact stiffness between the advance support equipment of fully mechanized excavation and the surrounding rock, thus affecting the dynamic characteristics of the advance support equipment during operation [3]. The over-underexcavation of the roadway leads to the uneven thickness of the shotcrete structure layer 
of the initial support, which affects the mechanical properties of the supporting structure and the stability of the surrounding rock [4].

Thus, it can be seen that the roadheader should ensure low surface roughness at the initial stage of cutting roadway. At present, a lot of research has been done on the kinematics, dynamics, and forming control of roadheader [5-14]. However, there is basically no research on the surface morphology of roadway cut by roadheader. Therefore, through the research on the characteristics of the forming outer profile of the roadway of the partial cross-section roadheader, this paper provides the basis for the optimization of the cutting parameters of the roadheader and the research of the high-precision forming control method, so as to reduce the roughness of the roadway surface. It is a basic problem that must be solved in coal mining.

This paper mainly studies the trajectory modeling method of cutting head, the mathematical model of cutting roadway outer contour, and the simulation method of roadway outer contour. This paper focuses on the creation mechanism of the outer contour of the roadway obtained by the cutting head, the dynamic modeling and solution of the cutting part, the geometric description of the outer profile of the cutting head, and the transformation of the motion coordinate system of the cutting part. By using the robot kinematics analysis method, the motion trajectory of the cutting head of the roadheader is accurately described, the mathematical model of the cutting head cutting the outer contour of the roadway is constructed, and the shape information of the outer contour of the roadway is obtained. Based on this analysis, the characteristics of the formed outer contour of the roadway under the influence of the vibration of the cutting head are analyzed, which has a certain guiding significance for improving the flatness and accuracy of the outer contour of the heading roadway.

\section{Roadway Forming Mechanism under the Cutting Action of Roadheader}

The roadheader cutting coal and rock to form the roadway surface is a complex process, which is affected by the geometric factors caused by the kinematics of the roadheader and the cutting phenomenon caused by the cutting head and the coal-rock coupling dynamics in the cutting process. The so-called geometric factors are the factors that affect the roadway surface shape from the point of view of the movement of the cutting head relative to the roadway coal and rock, such as the position of the roadheader, the lifting angle of the cutting part, the shape size of the cutting head, and the cutting feed step. The so-called cutting phenomenon refers to the vibration and plastic deformation of coal and rock in the cutting process, which will affect the shaping morphology of the roadway surface.

In order to construct the mathematical model and simulation model of cutting head cutting roadway outer profile, it is necessary to study the formation mechanism of roadway surface topography, and the roof forming process of driving roadway is shown in Figure 1.
In Figure $1, h_{f}$ is the residual height of the feed interval. Observing the residue of the first cut feed and the first cut feed (green filling in the picture), we can see that, after each cut, a "pit" is formed in the coal and rock and a "peak ridge" is raised between the adjacent "pits." The shape, size/height of the "pit" and "peak ridge" are related to the cutting feed, the cutting angle, the shape of the cutting head, the radius of the cutting head, and the cone angle of the cutting head. The residual coal and rock of the adjacent cutting feed constitute the residue of the feed interval. The regular distribution of residual coal and rock in three-dimensional space forms the surface texture, and its ups and downs form a twodimensional microprofile.

The right side of the figure shows the schematic diagram of the outer outline of the roadway without considering the cutting vibration and taking into account the cutting vibration. It can be seen from the figure that there are rules to follow in the formation of "pits" and "peak ridges" on coal and rock after cutting and feeding many times without considering vibration, and their height is basically the same. Considering the different heights of "pits" and "ridges" in the case of cutting vibration, it is necessary to analyze the vibration of the cutting head. If the vibration swing angle of the cutting head is large, the "pit" formed on the coal and rock will be deep, and if the vibration swing angle of the next feed cutting head is small, the "peak ridge" will be formed on the coal and rock.

\section{Vibration Analysis of Cutting Head in Cutting Process}

3.1. Cutting Load. When the cutting head of the roadheader is working, the cutting section of the cutter is in the shape of a crescent moon. When the cutting head is rotated, the cutting thickness $h$ of the cutter at different angles $\varphi_{i}$ also changes continuously, thus affecting the pick load at different positions. When the cutting head of the roadheader is driving, the position of different cutters changes with the angle of the cutters, and the number of cutters participating in the cutting changes at different moments. At a certain time, the $i$ cutter (the circumferential angle $\varphi_{i}$ on the cutting head) is projected by cutting resistance $Z_{i}$, traction resistance $Y_{i}$, and lateral resistance $X_{i}$, along the vertical direction $a$, feed direction $b$, and axial $c$ of the drum, and the components $F_{a j}, F_{b j}$, and $F_{c}$ are obtained. The cutting load of the cutting head is obtained by summing all the cutters involved in the cutting.

Through the above analysis, it is concluded that the cutting load of the cutting head is the sum of the forces of all the cutters involved in the cutting. According to the principle of force line translation, the forces of all the cutters are equivalent to the rotary center of the big end face of the cutting head, and the instantaneous cutting load of the cutting head can be obtained. When the cutting head rotates to a certain position, the force acting on the cutting head is shown in Figure 2, and the radial resistance $F_{a j}$, cutting resistance $F_{b j}$, and axial resistance $F_{c j}$ are obtained as follows: 


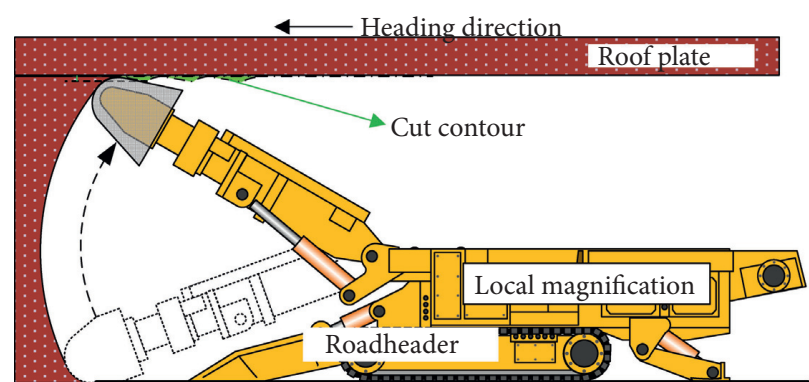

(a)

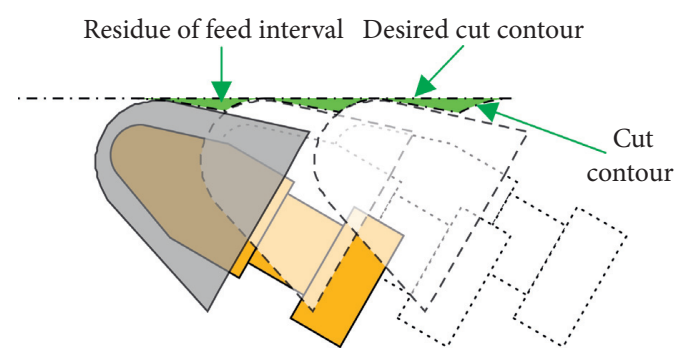

(b)

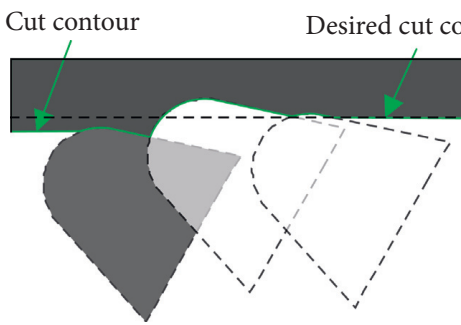

(c)

FIGURE 1: Schematic diagram of roof forming process of driving roadway. (a) Schematic diagram of roadheader work. (b) Cut contour without considering cutting vibration. (c) Cut contour with considering cutting vibration.
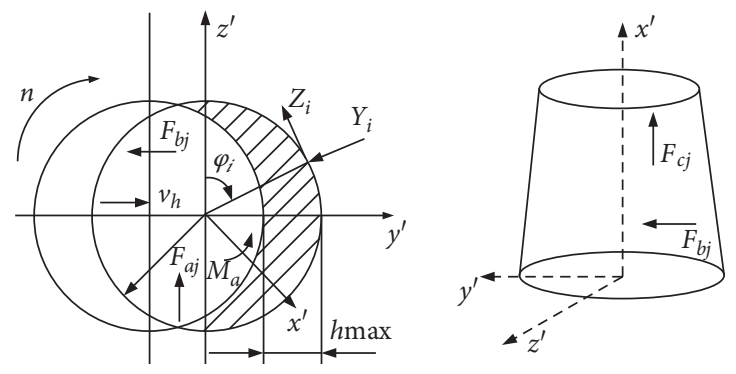

Figure 2: Transverse swing of cutting head.

$$
\left\{\begin{array}{l}
F_{a j}=\sum_{i=1}^{j}\left(-Y_{i} \cos \varphi_{i} \cos \beta_{i}+Z_{i} \sin \varphi_{i}\right), \\
F_{b j}=\sum_{i=1}^{j}\left(Y_{i} \sin \varphi_{i} \cos \beta_{i}+Z_{i} \cos \varphi_{i}\right), \\
F_{c j}=\sum_{i=1}^{j} X_{i}=\sum_{i=1}^{j} Y_{i} \sin \beta_{i} .
\end{array}\right.
$$

\subsection{Construction of Vertical Dynamic Model of Cutting Part.}

The working environment of the roadheader is bad, the working condition is complex, and the structure of the whole model of the roadheader is also relatively complex. In order to solve the problem, the dynamic model is simplified and the cutting part is regarded as a rigid body rotating around a fixed point. And, the mass of the cantilever section and the cutting head of the cutting part are concentrated in their respective centroids, and the lifting hydraulic cylinder is equivalent to a hydraulic spring with damping. Then, the dynamic model of the vertical direction of the cutting part is shown in Figure 3.

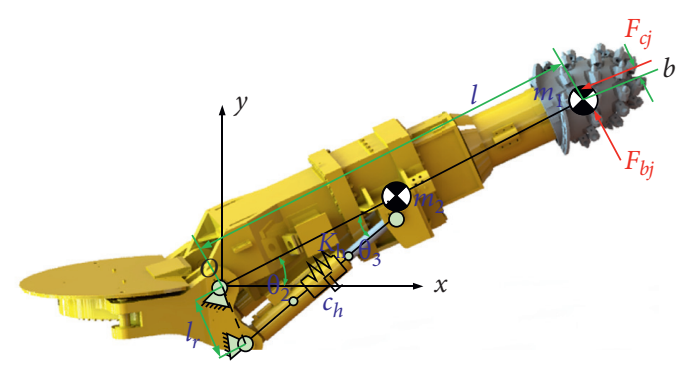

Figure 3: Vertical dynamic model of cutting part.

According to the relevant knowledge of mechanical vibration, Newton's second law can be used to list the vibration equation of the cutting part as follows:

$$
J \ddot{\theta}+k_{h} x l_{r} \cos \theta_{3}+c_{h} \dot{x} l_{r} \cos \theta_{3}=\sum M .
$$

In the formula, $J$ is the moment of inertia of the cutting head and the cantilever around the rotation point $\mathrm{O}, \ddot{\theta}$ is the angular acceleration of the rotation of the cutting part around the rotation point, and $k_{h}$ is the stiffness of the 
equivalent hydraulic spring, which can be calculated according to

$$
k_{h}=\frac{4 \beta_{e} A_{p}^{2}}{V_{t}}
$$

In the formula, $\beta_{e}$ is the effective volumetric elastic modulus of hydraulic oil, $A_{p}$ is the average acting area of the two cavities of the hydraulic cylinder, and $V_{t}$ is the average value of the equivalent total volume of the two cavities:

$$
V_{t}=A_{p} S \text {. }
$$

In the formula, $S$ is the stroke of the hydraulic cylinder. $c_{h}$ is the viscous damping coefficient of the hydraulic oil in the hydraulic cylinder. $x$ is the displacement of the hydraulic cylinder. $\dot{x}$ is the moving speed of the hydraulic cylinder. $\theta_{2}$ is the angle between the cutting part and the horizontal plane. $\theta_{3}$ is the angle between the lifting cylinder and the cutting part. $l_{r}$ is the distance between the rotation point of the cutting part and the rotation point of the lifting cylinder. $\sum M$ is the sum of all external moments to the rotation point.

Because the vibration swing angle $\theta$ of the cantilever section is small, it can be approximately considered that sin $\theta=\theta$; then, the displacement $x$ of the hydraulic cylinder is

$$
\begin{aligned}
x & =l_{r} \sin \theta \\
& =l_{r} \theta .
\end{aligned}
$$

The moving speed of the lifting hydraulic cylinder is

$$
\dot{x}=l_{r} \dot{\theta} \text {. }
$$

The moment of inertia $J$ of the cutting head and the cantilever section to the rotation point $O$ is

$$
\begin{aligned}
J & =m_{1} l^{2}+m_{2}\left(\frac{l}{2}\right)^{2} \\
& =\frac{\left(4 m_{1}+m_{2}\right) l^{2}}{4} .
\end{aligned}
$$

In the formula, $m_{1}$ and $m_{2}$ are the concentrated mass of the cutting head and the cantilever section, respectively, and it is assumed that the center of mass of the cantilever section is at the middle point.

According to the above analysis, we can obtain that the vibration equation when the cantilever segment is regarded as rotating a rigid body around a fixed point is

$$
\frac{\left(4 m_{1}+m_{2}\right) l^{2}}{4} \ddot{\theta}+l_{r}^{2} \cos \theta_{3} k_{h} \theta+l_{r}^{2} \cos \theta_{3} c_{h} \dot{\theta}=b F_{c j}+l F_{b j} .
$$

Based on the fourth-order and five-stage Runge-Kutta variable step size algorithm, the ode 45 function in Matlab is used to solve the vibration of the system numerically. The simulation parameters are shown in Table 1.

For the external load of the cutting head, the threedimensional load calculation formula of the cutting head in
TABLE 1: Simulation parameters.

\begin{tabular}{lc}
\hline Parameters & Numerical value \\
\hline$m_{1}$ & $2500 \mathrm{~kg}$ \\
$m_{2}$ & $4500 \mathrm{~kg}$ \\
$l$ & $4.2 \mathrm{~m}$ \\
$J$ & $63945 \mathrm{~kg} \cdot \mathrm{m}^{2}$ \\
$b$ & $0.2 \mathrm{~m}$ \\
$\beta_{e}$ & $1500 \mathrm{MPa}$ \\
$A_{p}$ & $0.025446 \mathrm{~m}^{2}$ \\
$V_{t}$ & $0.0076 \mathrm{~m}^{3}$ \\
$l_{r}$ & $0.57 \mathrm{~m}$ \\
$c_{h}$ & $100 \mathrm{~Pa} \cdot \mathrm{s}$ \\
$k_{h}$ & $511.18 \mathrm{MPa} / \mathrm{m}$ \\
\hline
\end{tabular}

the aforementioned formula (1) is substituted into the dynamic equation of the vibration of the cutting part, and the time is taken to analyze the dynamic response of the system. The results are shown in Figure 4.

Through the analysis of the vertical vibration response of the cutting part of the roadheader, the maximum positive vibration swing angle of the cutting head is $4.72^{\circ}$ and the maximum negative vibration swing angle is $-1.23^{\circ}$. The vertical vibration swing angle of the statistical cutting part under different cylinder pressures and different horizontal and vertical angles in the cutting space is shown in Figure 5.

The vertical vibration swing angle of the cutting part under different lifting cylinder pressure and different horizontal and vertical angles in the cutting space shows that when the vertical swing angle of the cutting part is constant and the horizontal swing angle is 0 , the vertical vibration of the cutting part is the most intense. When the horizontal swing angle of the cutting part is constant and the vertical swing angle is 0 , the vertical vibration of the cutting part is the smallest. The main reason is that the vibration intensity of the cutting part is affected by the cutting load. With the increase of the pressure of the lifting cylinder, the greater the stiffness of the swing vibration system of the cutting part is, the lower the vertical vibration swing angle of the cutting part is.

\section{Kinematic Model of Cutting Head}

The coordinate system of roadheader is defined as $O_{0} X_{0} Y_{0} Z_{0}$, the spatial coordinate system of roadway is $O X Y Z$ and the coordinate system of each mechanism of roadheader is $O_{i} X_{i} Y_{i} Z_{i}$, where $i=1$ represents the turntable coordinate system, $i=2$ represents the cutting part coordinate system, $i=3$ represents the telescopic part coordinate system of the cutting part, and $i=4$ represents the cutting head coordinate system. The relationship between the various coordinate systems is shown in Figure 6.

After the establishment of the above coordinate systems, the motion and attitude relationship of the roadheader cutting head relative to the roadway space can be determined, and the kinematics loop of the roadheader is established systematically.

The kinematics system of the roadheader belongs to the open-chain system, and the movement of the cutting head 


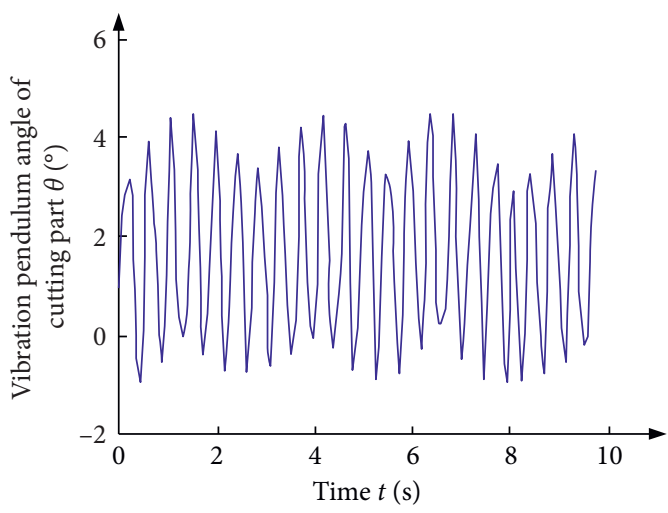

FIGURE 4: Vertical vibration swing angle of cutting part.

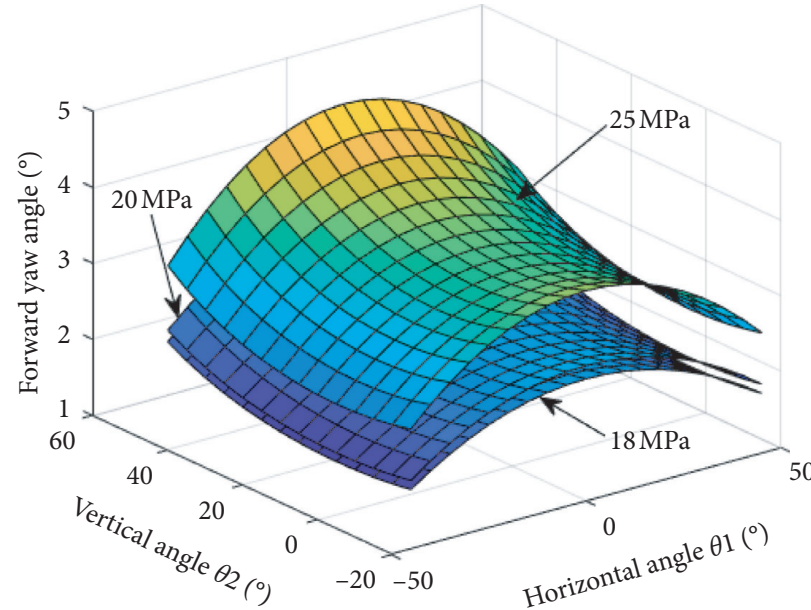

(a)

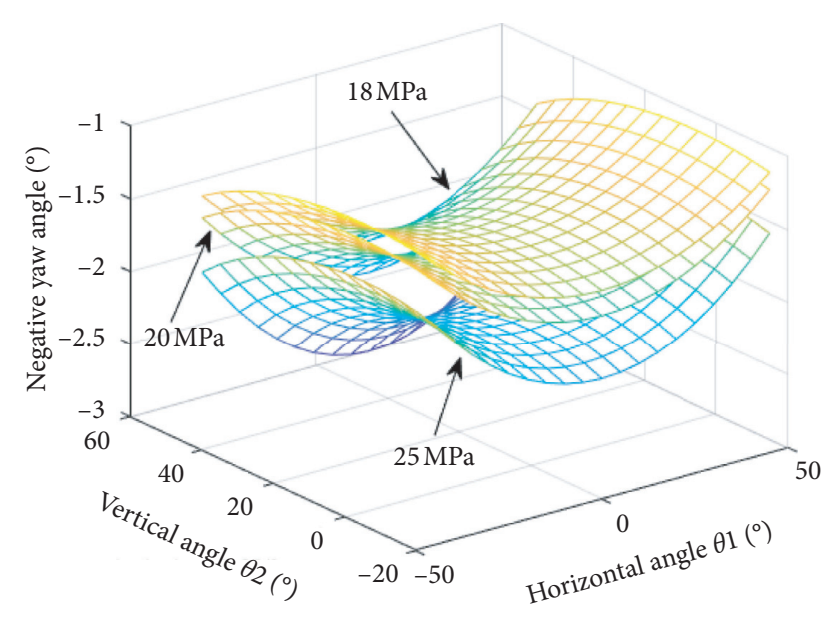

(b)

FIGURE 5: Vertical vibration swing angle of cutting part. (a) Forward swing angle. (b) Negative swing angle.

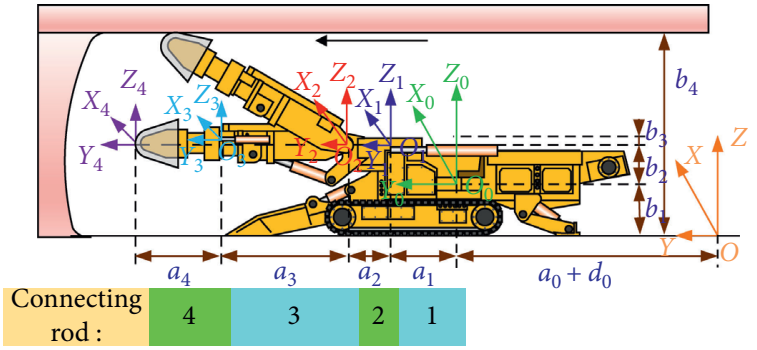

FIgURE 6: Kinematic coordinate system of roadheader.

cutting roadway is controlled by the rotation of the turntable (horizontal rotation angle $\theta_{1}$ ), the rise and fall of the cutting part (vertical lifting angle $\theta_{2}$ ), the movement of the telescopic part $(d)$, and the movement of the roadheader fuselage relative to the roadway (cutting feed $d_{0}$ ). The movements of each mechanism belong to series. The kinematics analysis of the cutting head of the roadheader is carried out by using the Dmurh method in robotics $[15,16]$. According to the Dmurh method, the displacement of the moving joint and the rotation angle of the rotating joint can be transformed into the coordinates of the cutting head to describe the position and attitude of the cutting head relative to the roadheader and roadway. The homogeneous transformation matrix for describing the cutting head in the roadway coordinate system is

$$
\begin{aligned}
{ }_{4}^{\mathrm{T}} & ={ }_{0} \mathrm{~T}_{1}^{0} \mathrm{~T}_{2}^{1} \mathrm{~T}_{3}^{2} \mathrm{~T}_{4}^{3} \mathrm{~T} \\
& =\left[\begin{array}{cccc}
\cos \theta_{1} & -\sin \theta_{1} \cos \theta_{2} & \sin \theta_{1} \sin \theta_{2} & -\left(a_{3}+a_{4}+d\right) \sin \theta_{1} \cos \theta_{2}-a_{2} \sin \theta_{1} \\
\sin \theta_{1} & \cos \theta_{1} \cos \theta_{2} & -\cos \theta_{1} \sin \theta_{2} & \left(a_{3}+a_{4}+d\right) \cos \theta_{1} \cos \theta_{2}+a_{2} \cos \theta_{1}+a_{1}+a_{0}+d_{0} \\
0 & \sin \theta_{2} & \cos \theta_{2} & \left(a_{3}+a_{4}+d\right) \sin \theta_{2}+b_{2}+b_{1}+b_{3} \\
0 & 0 & 0 & 1
\end{array}\right],
\end{aligned}
$$


where ${ }_{0} \mathbf{T}=\left[\begin{array}{cccc}1 & 0 & 0 & 0 \\ 0 & 1 & 0 & a_{0}+d_{0} \\ 0 & 0 & 1 & b_{1} \\ 0 & 0 & 0 & 1\end{array}\right],{ }_{1}^{0} \mathbf{T}=\left[\begin{array}{cccc}\cos \theta_{1} & -\sin \theta_{1} & 0 & 0 \\ \sin \theta_{1} & \cos \theta_{1} & 0 & a_{1} \\ 0 & 0 & 1 & b_{2} \\ 0 & 0 & 0 & 1\end{array}\right],{ }_{2}^{1} \mathbf{T}=$ $\left[\begin{array}{cccc}1 & 0 & 0 & 0 \\ 0 & \cos \theta_{2} & -\sin \theta_{2} & a_{2} \\ 0 & \sin \theta_{2} & \cos \theta_{2} & b_{3} \\ 0 & 0 & 0 & 1\end{array}\right],{ }_{3}^{2} \mathbf{T}=\left[\begin{array}{cccc}1 & 0 & 0 & 0 \\ 0 & 1 & 0 & a_{3}+d \\ 0 & 0 & 1 & 0 \\ 0 & 0 & 0 & 1\end{array}\right],{ }_{4}^{3} \mathbf{T}=\left[\begin{array}{llll}1 & 0 & 0 & 0 \\ 0 & 1 & 0 & a_{4} \\ 0 & 0 & 1 & 0 \\ 0 & 0 & 0 & 1\end{array}\right], \theta_{1}$ is horizontal rotation angle, $\theta_{2}$ is vertical lifting angle, and $d_{0}$ is cutting feed.

If the coordinate vector set at the center of the cutting head in the cutting head coordinate system is ${ }^{4} \mathbf{p}=$ $\left[\begin{array}{llll}0 & 0 & 0 & 1\end{array}\right]^{T}$, it can be transformed into the coordinate system of the roadway by the following formula:

$$
\mathbf{p}={ }_{4} \mathbf{T} \cdot{ }^{4} \mathbf{p}=\left[\begin{array}{llll}
x & y & z & 1
\end{array}\right]^{\mathrm{T}},
$$

where $x=-\left(a_{3}+a_{4}+d\right) \sin \theta_{1} \cos \theta_{2}-a_{2} \sin \theta_{1}, y=\left(a_{3}+\right.$ $\left.a_{4}+d\right) \cos \theta_{1} \cos \theta_{2}-a_{2} \cos \theta_{1}+a_{1}+a_{0}+d_{0}$ and $z=\left(a_{3}\right.$ $\left.+a_{4}+d\right) \sin \theta_{2}+b_{2}+b_{1}+b_{3}$.

$\left\{{ }^{4} \mathbf{p}_{O_{4}}=\left[\begin{array}{llll}0 & 0 & 0 & 1\end{array}\right],{ }^{4} \mathbf{p}_{O_{j}}=\left[\begin{array}{llll}0 & -r_{1} & 0 & 1\end{array}\right],{ }^{4} \mathbf{p}_{C_{1}}=\left[\begin{array}{lll}0 & -r_{1}(1-\cos \alpha)\end{array}\right.\right.$

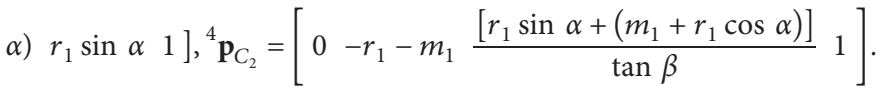

From the kinematic model of the cutting head, we can know that the coordinate transformations of $C_{1}$, and $C_{2}$ relative to the roadway coordinate system are as follows:

$$
\begin{aligned}
& \left\{\begin{array}{l}
X_{C_{1}}=-r_{1}(1-\cos \alpha) u_{2}+u_{3} r_{1} \sin \alpha+u_{4}, \\
Y_{C_{1}}=-r_{1}(1-\cos \alpha) v_{2}+v_{3} r_{1} \sin \alpha+v_{4}, \\
Z_{C_{1}}=r_{1}(1-\cos \alpha) w_{2}+w_{3} r_{1} \sin \alpha+w_{4},
\end{array}\right. \\
& \left\{\begin{array}{l}
X_{C_{2}}=-\left(r_{1}+m_{1}\right) u_{2}+\frac{\left[r_{1} \sin \alpha+\left(m_{1}+r_{1} \cos \alpha\right)\right]}{\tan \beta} u_{3}+u_{4}, \\
Y_{C_{2}}=-\left(r_{1}+m_{1}\right) v_{2}+\frac{\left[r_{1} \sin \alpha+\left(m_{1}+r_{1} \cos \alpha\right)\right]}{\tan \beta}, \\
Z_{C_{2}}=-\left(r_{1}+m_{1}\right) w_{2}+\frac{\left[r_{1} \sin \alpha+\left(m_{1}+r_{1} \cos \alpha\right)\right]}{\tan \beta} w_{3}+w_{4},
\end{array}\right.
\end{aligned}
$$

where $\quad u_{1}=\cos \theta_{1}, \quad u_{2}=-\sin \theta_{1} \cos \theta_{2}, \quad u_{3}=-\sin \theta_{1} \sin \theta_{2}$, $u_{4}=-\left(a_{3}+a_{4}+d\right) \quad \sin \theta_{1} \cos \theta_{2}-a_{2} \sin \theta_{1}, \quad v_{1}=\sin \theta_{1}$, $v_{2}=\cos \theta_{1} \cdot \cos \theta_{2}, \quad v_{3}=-\cos \theta_{1} \sin \theta_{2}, \quad v_{4}=\left(a_{3}+a_{4}+d\right)$ $\cos \theta_{1} \cos \theta_{2}+a_{2} \cdot \cos \theta_{1}+a_{1}+a_{0}+d_{0}, \quad w_{1}=0, \quad w_{2}=\sin \theta_{2}$, $w_{3}=\cos \theta_{2}$, and $w_{4}=\left(a_{3}+a_{4}+d\right) \sin \theta_{2}+b_{2}+b_{1}+b_{3}$.

The coordinates of point $\mathrm{O}_{4}$ are as follows:

\section{Cutting Surface Contour Model}

In the process of roadway surface topography research, the establishment of accurate roadway model and cutting head motion model is the basis of simulation, and how to find out the intersection of cutting head motion model and roadway model is the key of the whole simulation work. In this section, we will construct the cutting surface contour model obtained by the intersection of the cutting head motion model and the roadway model.

This paper takes the common "ball crown + cone" cutting head of roadheader as the research object. Select the key nodes $\mathrm{O}_{4}, \mathrm{O}_{j}, \mathrm{C}_{1}, \mathrm{C}_{2}$, and $\mathrm{C}_{3}$ above the cutting head, and the key node coordinates on the profile are defined as shown in Figure 7.

From the geometry of the "ball crown + cone" cutting head, it is known that the coordinate vectors of $O_{4}, O_{j}, C_{1}$, and $C_{2}$ in the coordinate system of the cutting head are as follows:

$$
\begin{gathered}
X_{O_{4}}=u_{4}, \\
Y_{O_{4}}=v_{4}, \\
Z_{O_{4}}=w_{4}, \\
X_{O_{j}}=-r_{1} u_{2}-X_{O_{4}}, \\
Y_{O_{j}}=-r_{1} v_{2}-Y_{O_{4}}, \\
Z_{O_{j}}=-r_{1} w_{2}-Z_{O_{4}} .
\end{gathered}
$$

Because the cutting head is a rotary body, it is considered that the outer profile of coal and rock formed by the cutting head is determined by the arc $O_{4} C_{1}$, line $C_{1} C_{2}$, and line $C_{2} C_{3}$ on the section of the cutting head, as shown in Figure 8.

The outer contour equation of the "ball crown + cone" cutting head is as follows:

$$
\left\{\begin{array}{l}
O_{4} C_{1}: Z=Z_{O j}+r_{1} \sin \left(\arccos \frac{Y-Y_{O j}}{r_{1}}\right), \\
Y_{O j}+r_{1} \cos \theta_{2} \leq Y \leq Y_{O j}+r_{1} \cos \left(\theta_{2}+\alpha\right), \\
C_{1} C_{2}: Z=\frac{Z_{C 2}-Z_{C 1}}{Y_{C 2}-Y_{C 1}}\left(Y-Y_{C 2}\right)+Z_{C 1}, \\
Y_{C 1} \leq Y \leq Y_{C 2} .
\end{array}\right.
$$




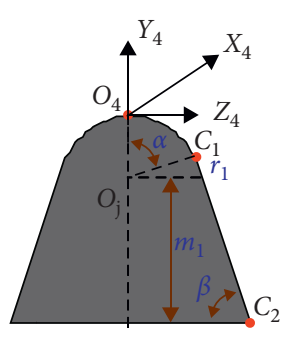

Figure 7: Type and coordinate definition of cutting head.

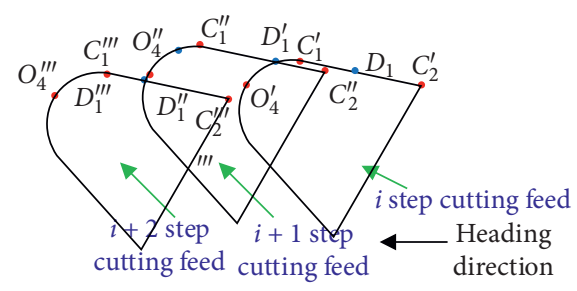

Figure 8: Cutting head cutting roadway forming profile.

Usually, the feed rate of one cutting head of the roadheader is about $550 \mathrm{~mm}$, and the outer contours of the cutting head obtained by two cutting feeds will intersect at the intersection point $D_{1}$ of the arc $O_{4} C_{1}$ and the line segment $C_{1} C_{2}$ on the cutting head of the previous cutting feed.

Then, the outer outline formed by the cutting head cutting coal and rock is a combination of line segments or arcs: $\cdots D_{1}^{\prime} C_{1}^{\prime} D_{1}^{\prime \prime} C_{1}^{\prime \prime} D_{1}^{\prime \prime} C_{1}^{\prime \prime} \cdots$. Then, the outer profile of coal and rock formed by the formula can be described as

$$
\left\{\begin{array}{l}
\vdots \\
C_{1}^{\prime} D_{1}^{\prime}: Z=Z_{O_{l} j}+r_{1} \sin \left(\arccos \frac{Y-Y_{O_{l} j}}{r_{1}}\right), \quad Y_{C_{1}^{\prime}} \leq Y \leq Y_{D_{1}^{\prime}}, \\
D_{1}^{\prime} C_{1}^{\prime \prime}: Z=\frac{Z_{C_{1}^{\prime \prime}}-Z_{D_{1}^{\prime}}}{Y_{C_{1}^{\prime \prime}}-Y_{D_{1}^{\prime}}}\left(Y-Y_{C_{1}^{\prime \prime}}\right)+Z_{D_{1}^{\prime},} \quad Y_{D_{1}^{\prime}} \leq Y \leq Y_{C_{1}^{\prime \prime}}, \\
C_{1}^{\prime \prime} D_{1}^{\prime \prime}: Z=Z_{O_{\prime \prime} j}+r_{1} \sin \left(\arccos \frac{Y-Y_{O_{\prime \prime} j}}{r_{1}}\right), \quad Y_{C_{1}^{\prime \prime}} \leq Y \leq Y_{D_{1}^{\prime \prime}}, \\
D_{1}^{\prime \prime} C_{1}^{\prime \prime}: Z=\frac{Z_{C_{1}^{\prime \prime \prime}}-Z_{D_{1}^{\prime \prime}}}{Y_{C_{1}^{\prime \prime}}-Y_{D_{1}^{\prime \prime}}}\left(Y-Y_{C_{1}^{\prime \prime}}\right)+Z_{D_{1}^{\prime \prime}}, \quad Y_{D_{1}^{\prime \prime}} \leq Y \leq Y_{C_{1}^{\prime \prime}}, \\
\vdots
\end{array}\right.
$$

\section{Simulation Analysis of the Characteristics of the Outer Profile of Roadway Forming}

In this paper, taking the EBZ200 roadheader commonly used in coal mine as the research object, the simulation program of the outer profile of coal and rock is built in the MATLAB numerical calculation software, and the parameters in the simulation program are set by the structure size of EBZ200 roadheader as follows: $a_{0}=0 \mathrm{~mm}, a_{1}=3000 \mathrm{~mm}$, $a_{2}=700 \mathrm{~mm}, a_{3}=2470 \mathrm{~mm}, a_{4}=1775 \mathrm{~mm}, b_{1}=1000 \mathrm{~mm}$, $b_{2}=519 \mathrm{~m}, \quad b_{3}=87 \mathrm{~mm}, d=0 \mathrm{~mm}, \quad r_{1}=416 \mathrm{~mm}, \alpha=90^{\circ}$, $\beta=83.5$, and $m_{1}=640 \mathrm{~mm}$. The cutting feed rate $d_{0}$ is set to $550 \mathrm{~mm}$ and the cutting lifting angle is $42^{\circ}$. The simulation results show that the characteristics of the formed outer profile of the roadway considering the vibration of the cutting head and without considering the vibration of the cutting head are shown in Figure 9.

After each cut, a "pit" is formed in the coal and rock, and the "peak ridge" is raised between the adjacent "pits." The simulation results are consistent with the expected results shown in Figure 9. Considering the vibration of the cutting head, the difference between "pit" and "peak ridge" is larger. Without considering the vibration of the cutting head, the difference between the "pit" and the "peak ridge" is $105.6 \mathrm{~mm}$, while in the case of considering the vibration of the cutting head, the difference between the "pit" and the "peak ridge" is $435.1 \mathrm{~mm}$. It shows that the outer outline of the roadway obtained by real cutting is more rougher than that without considering the vibration of the cutting head, and it is not conducive to the accurate cutting and shaping of the roadway.

In order to quantify the characteristics of the formed outer profile of the roadway, the maximum difference between the "pit" and the uplift "peak ridge" formed on the coal and rock after cutting and the average value of the "pit" and the uplift "peak ridge" are selected as the evaluation parameters of the roadway surface topography:

$$
\begin{gathered}
R_{\max }=Z_{\max }-Z_{\min }, \\
R_{\mathrm{avg}}=\frac{\sum_{i=0}^{n} Z_{i}}{n},
\end{gathered}
$$

where $Z_{\min }$ is the maximum value of "pit," $Z_{\max }$ is the maximum value of "peak ridge," $Z_{i}$ is the value of roadway profile of each sampling point, and $n$ is the number of sampling points.

The cutting height is set to $[3600 \mathrm{~mm}, 3900 \mathrm{~mm}$, $4200 \mathrm{~mm}, 4500 \mathrm{~mm}$ ] to study the characteristics of the formed outer profile of the roadway under the condition of different roadway height and different stiffness of lifting cylinder, as shown in Figure 10.

According to formulas (13) and (14), it is calculated that when the horizontal swing angle is in the range of $-45^{\circ}$ to $45^{\circ}$ and the vertical swing angle is in the range of $25^{\circ}$ to $45^{\circ}$, the evaluation indexes of the forming outer profile characteristics of the roadway under the pressure of $18 \mathrm{MPa}, 20 \mathrm{MPa}$, and $25 \mathrm{MPa}$, respectively, are shown in Figure 11.

The numerical simulation shows that when the cylinder pressure is $18 \mathrm{MPa}, 20 \mathrm{MPa}$, and $25 \mathrm{MPa}$, respectively, the trend of the evaluation index of the forming outer profile of the roadway is basically the same with the increase of the cutting angle. The maximum difference between "pit" and uplift "peak ridge" on coal and rock and the average value of "pit" and uplift "peak ridge" all show an increasing trend and with the increase of cylinder pressure. The maximum 


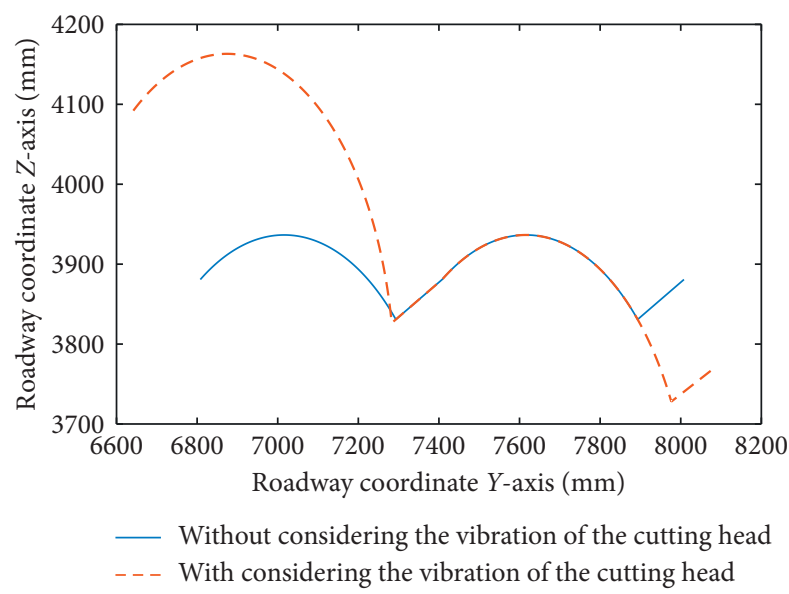

FIGURE 9: Simulation results of roadway surface morphology.

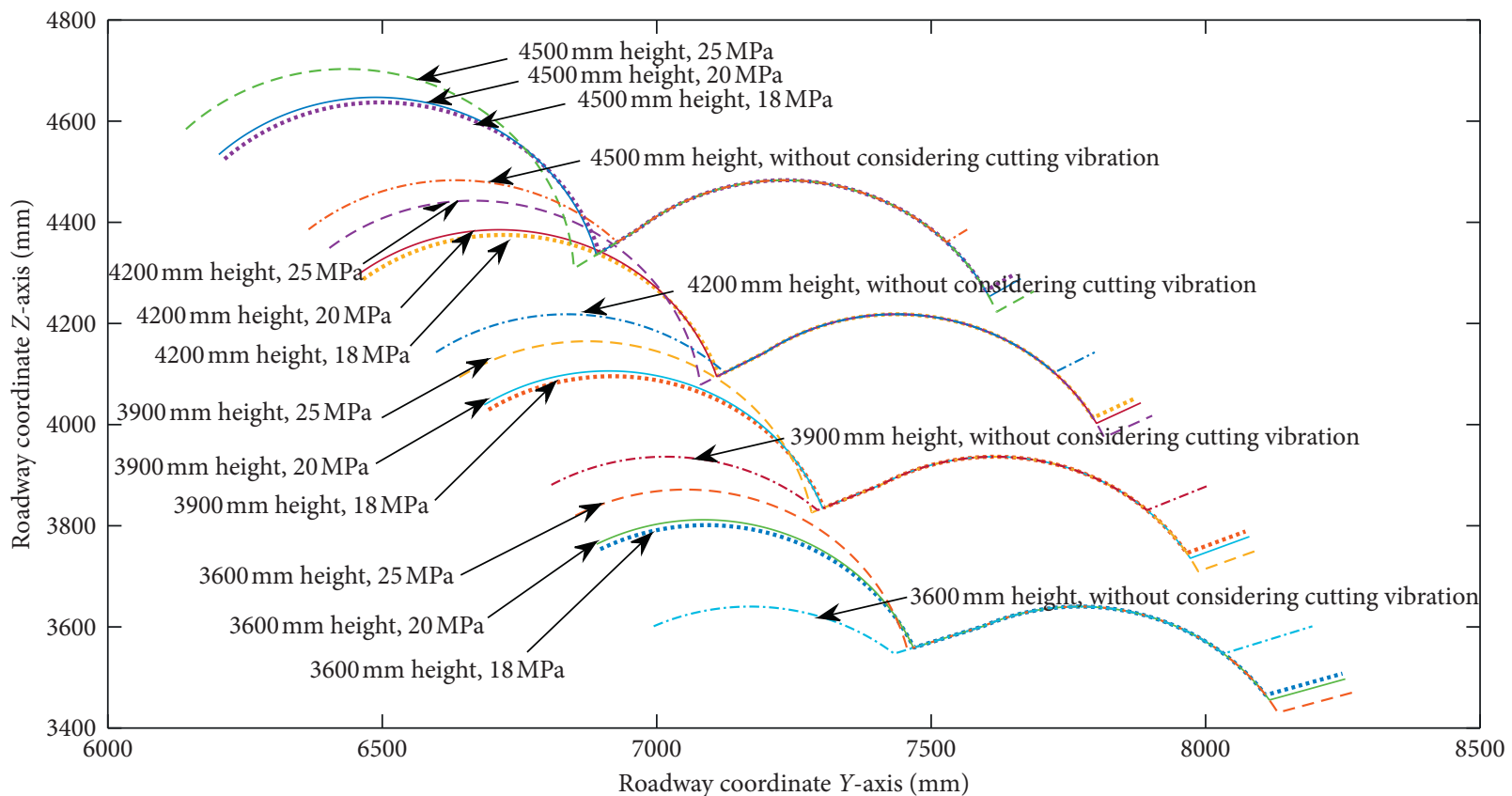

Figure 10: The effect of different cutting heights on contour features.

Rmax of the horizontal swing angle "pit" and the uplift "peak ridge" gradually increases, mainly due to the increase of the pressure of the lifting cylinder, which is equivalent to the increase of the cutting load, the vibration of the cutting part becomes intense, and the positive and negative swing angle of the cutting head increases, resulting in the increase of the maximum Rmax. When the horizontal swing angle of the cutting part is from $-45^{\circ}$ to $45^{\circ}$, the maximum $R \max$ increases at first and then decreases, which is mainly due to the change of cutting load. The average value of horizontal swing angle "pit" and uplift "peak ridge" is almost not affected by the change of cylinder pressure, indicating that the change of cutting load mainly affects the maximum value of "pit" and uplift "peak ridge" Rmax and has little effect on the average value of the formed outer profile of the roadway.

\section{Experimental Study}

The experimental study on the surface profile characteristics of roadway cut by roadheader is carried out by using the selfbuilt test-bed, and the experimental results are compared with the theoretical calculation results. The test-bed is mainly composed of roadheader model prototype, simulated coal wall, and roadway surface profile measurement platform. The prototype of the roadheader model is shown in Figure 12.

The platform of the roadheader is a self-made model prototype of the roadheader, and all the physical parameters are obtained by similar proportion conversion according to the parameters of the EBZ200 roadheader.

The roadway surface profile measuring platform is shown in Figure 13. 


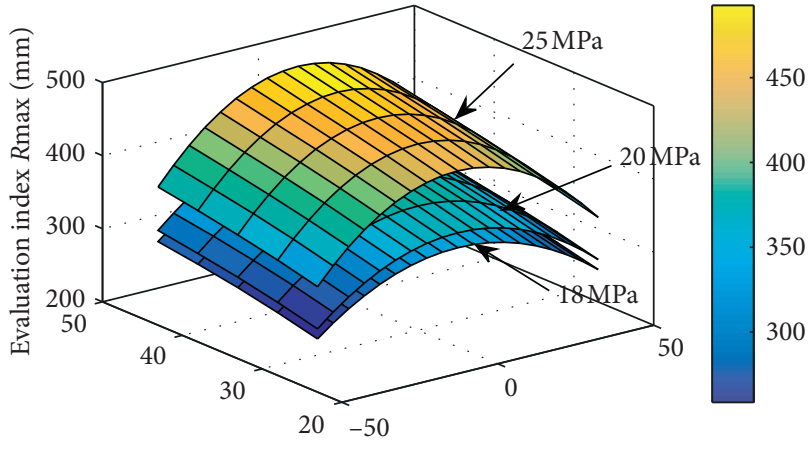

(a)

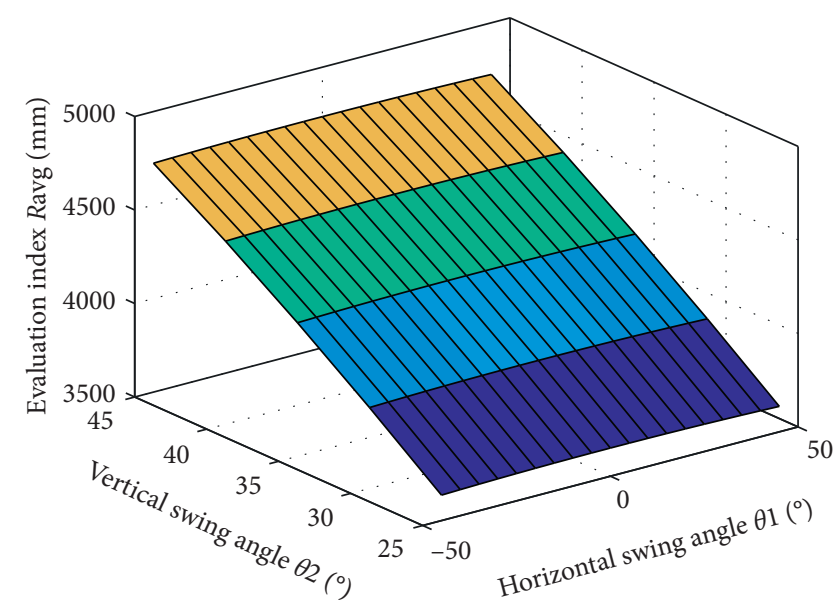

(c)

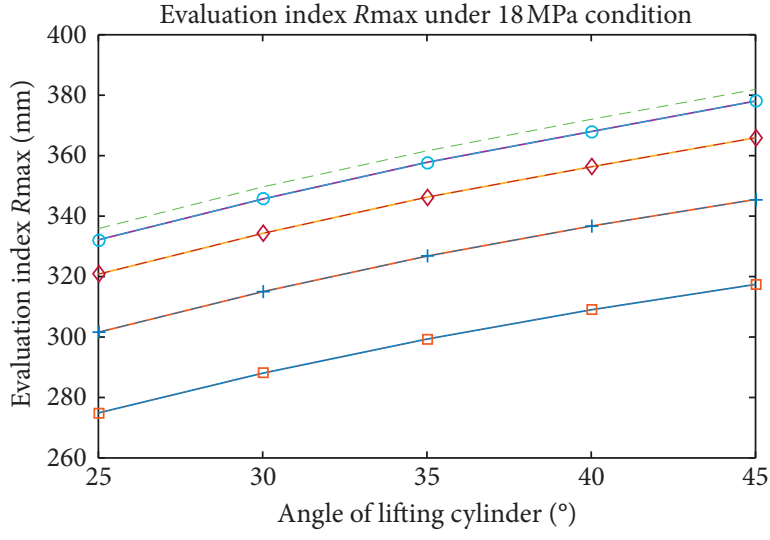

- Horizontal swing angle $=-40^{\circ}$

Horizontal swing angle $=-30^{\circ}$

Horizontal swing angle $=-20^{\circ}$

- Horizontal swing angle $=-10^{\circ}$

- Horizontal swing angle $=0^{\circ}$

$-\ominus-$ Horizontal swing angle $=10^{\circ}$

$-\diamond-$ Horizontal swing angle $=20^{\circ}$

-+- Horizontal swing angle $=30^{\circ}$

‥ Horizontal swing angle $=40^{\circ}$

(b)

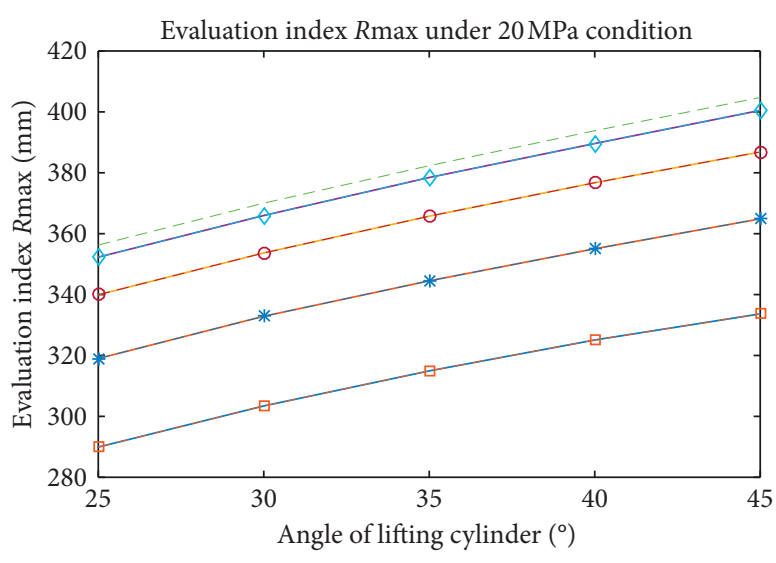

- Horizontal swing angle $=-40^{\circ}$

Horizontal swing angle $=-30^{\circ}$

Horizontal swing angle $=-20^{\circ}$

- Horizontal swing angle $=-10^{\circ}$

- - Horizontal swing angle $=0^{\circ}$

$-\diamond-$ Horizontal swing angle $=10^{\circ}$

$-\ominus-$ Horizontal swing angle $=20^{\circ}$

- $*$ - Horizontal swing angle $=30^{\circ}$

$-в-$ Horizontal swing angle $=40^{\circ}$

(d)

Figure 11: Continued. 

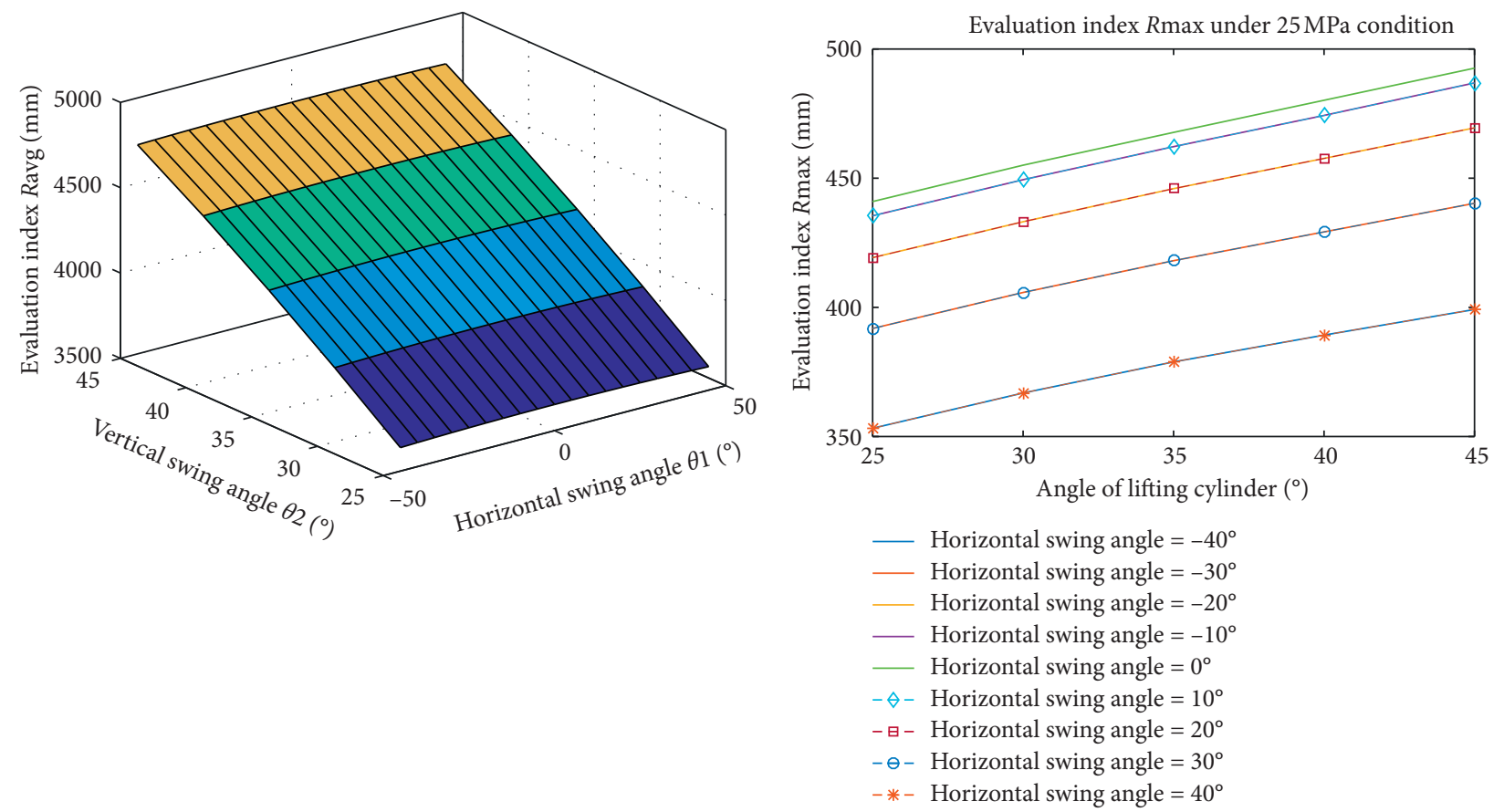

(e)

(f)

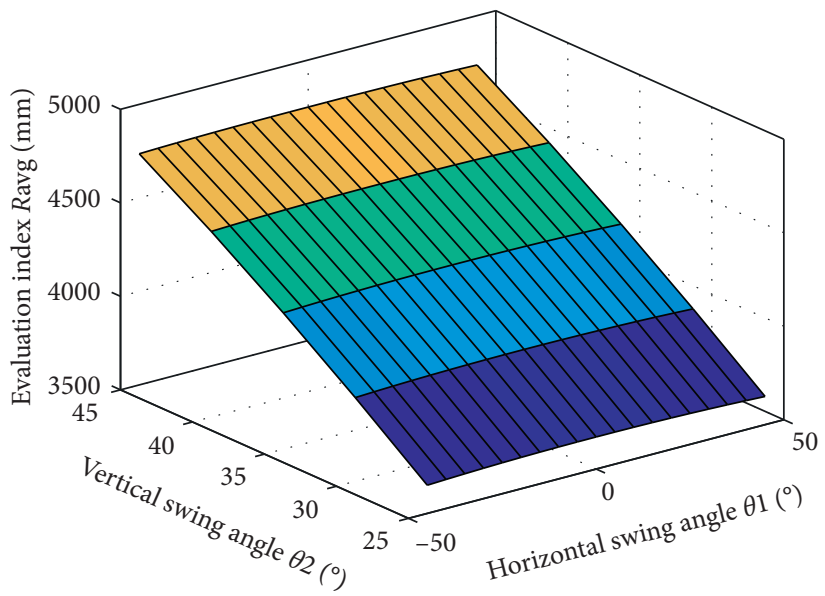

(g)

Figure 11: Evaluation indexes of outline features of roadway forming under different working conditions. (a) Three-dimensional diagram. (b) Evaluation index Rmax under $18 \mathrm{MPa}$ condition. (c) Evaluation index Ravg under $18 \mathrm{MPa}$ condition $18 \mathrm{MPa}$. (d) Evaluation index Rmax under $20 \mathrm{MPa}$ condition. (e) Evaluation index Ravg under $20 \mathrm{MPa}$ condition. (f) Evaluation index Rmax under $25 \mathrm{MPa}$ condition. (g) Evaluation index Ravg under $25 \mathrm{MPa}$ condition.

The simulated coal wall after cutting is scanned by using the biaxial linear sliding table of the test platform and its high precision laser displacement sensor. The uniaxial moving range of the two-axis linear slide table is $1000 \mathrm{~mm}$, the position accuracy of the linear screw slide table is $0.05 \mathrm{~mm}$, the repeated positioning accuracy is $0.02 \mathrm{~mm}$, and the moving speed is $100 \mathrm{~mm} / \mathrm{s}$. The detection distance of the high precision laser displacement sensor is $2000 \mathrm{~mm}$, the detection accuracy is $\pm 0.5 \mathrm{~mm}$, and the resolution is $1 \mathrm{~mm}$. The controller and data acquisition use Siemens S7-200 smart PLC.

The surface profile of the simulated coal wall cut by the roadheader is shown in Figure 14.
The experimental process is shown in Figure 15.

The comparison between the three-dimensional profile of the roadway surface measured by the experiment and the theoretical research results is shown in Figure 16.

The experimental results show that the errors of theoretical calculation and experimental test are mainly within $\pm 2 \mathrm{~mm}$. Generally speaking, the feasibility of the theoretical research method and the correctness of the results can be verified by experiments. In the follow-up research, the author will focus on how to optimize the geometric parameters of the cutting head and the motion parameters of the roadheader to obtain a lower roadway surface roughness and to achieve accurate autonomous cutting of the roadheader. 


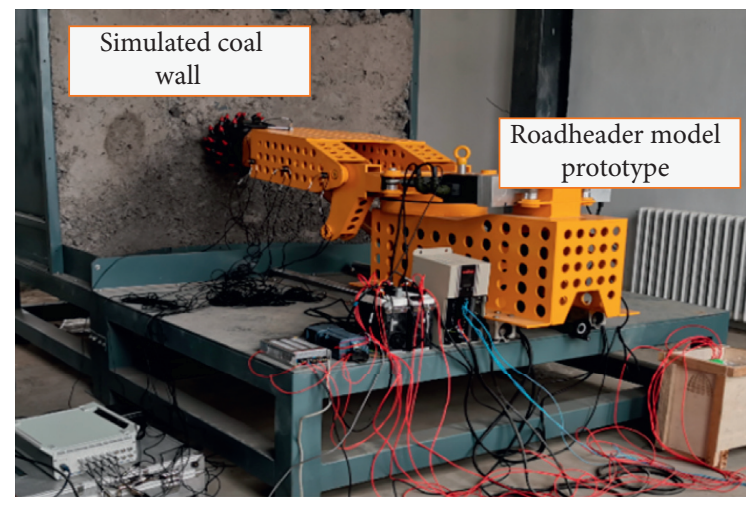

FIgURE 12: Roadheader model prototype and simulated coal wall.

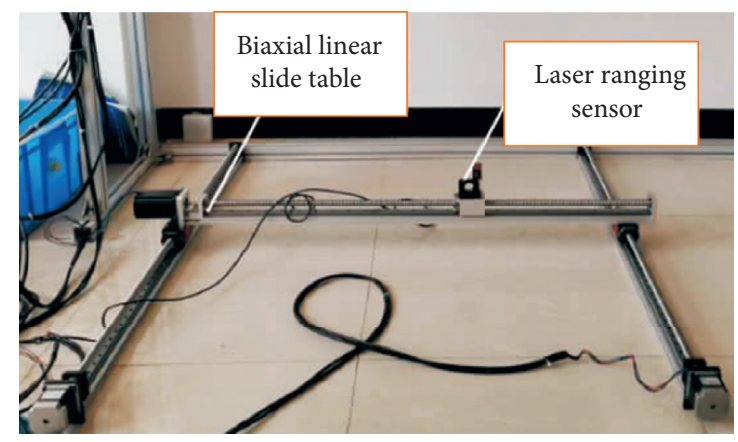

Figure 13: Roadway surface profile measurement platform.

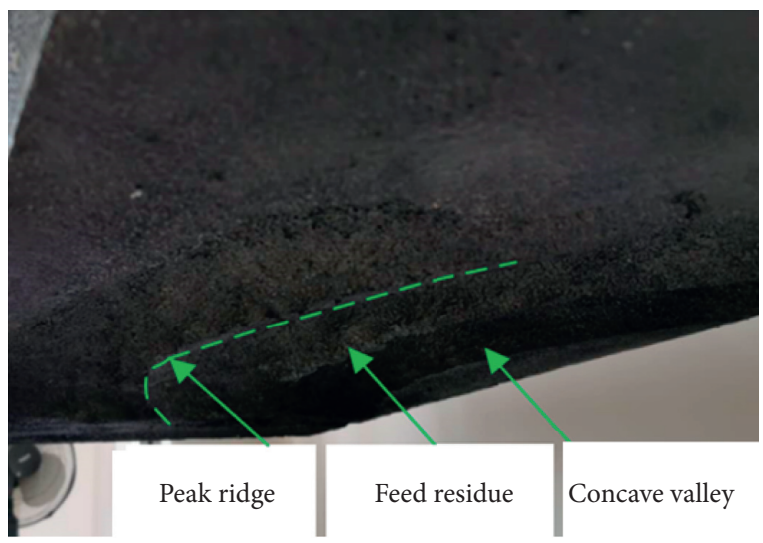

FIgURE 14: Simulated coal wall.

\section{Conclusion}

This paper mainly studies the trajectory modeling method of cutting head, the mathematical model of cutting roadway outer contour, and the simulation method of roadway outer contour. This paper focuses on the characteristics of the formed outer profile of the roadway under the influence of the vibration of the cutting head. The main results are as follows:

(1) By establishing and solving the dynamic model of the cutting part, when the vertical swing angle of the cutting part is constant and the horizontal swing angle is 0 , the vertical vibration of the cutting part is

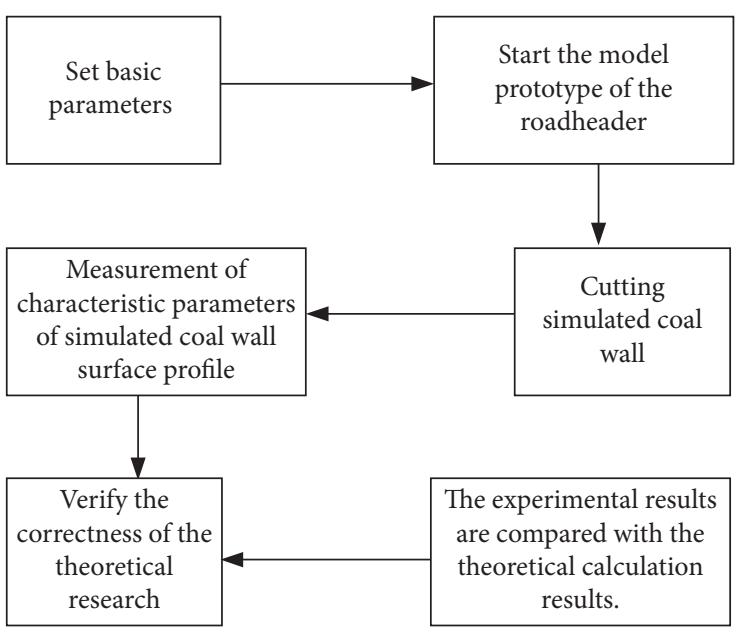

FIGURE 15: The experimental process.

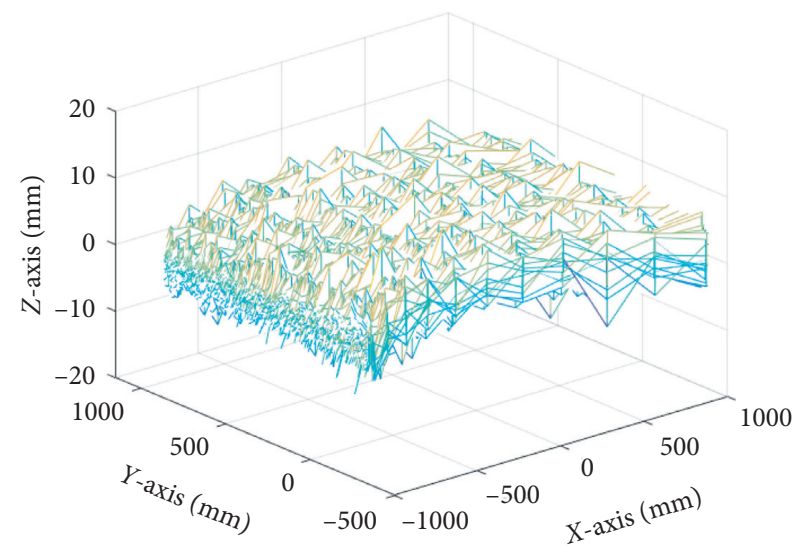

Figure 16: Comparison of experimental and theoretical results.

the most intense. When the horizontal swing angle of the cutting part is constant and the vertical swing angle is 0 , the vertical vibration of the cutting part is the smallest.

(2) Considering the vibration of the cutting head, the difference between the "pit" and the "peak ridge" obtained without considering the vibration is larger, indicating that the outer outline of the roadway obtained by the real cutting is more rougher than that without considering the vibration of the cutting head, which is not conducive to the accurate cutting of the roadway.

(3) The numerical simulation shows that the maximum and average value of the difference between "pit" and uplift "peak ridge" on coal and rock increases with the increase of cutting angle, and the maximum Rmax of horizontal swing angle "pit" and uplift "peak ridge" increases gradually with the increase of cylinder pressure.

(4) At present, there is basically no research on the surface morphology of roadway cut by roadheader in the existing research. In this paper, the characteristics of roadway forming outer contour of roadway 
cutting by roadheader were studied, and the influence of cutting vibration on roadway forming outer profile was studied.

(5) Through the research of this paper, the influence law of cutting vibration on the characteristics of forming outer profile was mastered. It can provide a basis for realizing accurate cutting, and through certain control methods, the surface roughness of heading roadway can be reduced. From [3], it can be known that the roadway surface roughness will affect the contact stiffness between the advance support equipment and the surrounding rock, thus affecting the dynamic characteristics of the advance support equipment during operation. Therefore, the research work of this paper has a certain positive significance for realizing the low disturbance operation of driving roadway.

\section{Data Availability}

There are no public data yet, but it will be made public on our website (http://kczyyjy.lntu.edu.cn/) one after another.

\section{Conflicts of Interest}

The authors declare that they have no conflicts of interest.

\section{Authors' Contributions}

Zhi-xiang Liu designed the research. Miao Xie processed the corresponding data. Zhi-xiang Liu wrote the first draft of the manuscript. Shuai Wang and Chun-xue Xie helped to organize the manuscript.

\section{Acknowledgments}

The authors would like to thank for the financial support provided by the National Natural Science Foundation of China (nos. 51904142 and 51874158) and Liaoning Natural Science Foundation Guidance Program (no. 2019-ZD-0036).

\section{References}

[1] Y. Huo, M. M. Fang, F. X. Liu, and Z. Xu, "Influence of wall roughness on electromagnetic wave propagation in coal mine tunnels," Industry and Mine Automation, vol. 39, no. 3, pp. 43-45, 2013.

[2] X. Y. Gong, G. Li, W. Y. Jiao, M. Jinming, Z. Yongqiang, and $\mathrm{X}$. Xinyu, "Influence of wall roughness on restricted wallattached turbulent jet in excavation roadway," Mining Safety \& Environmental Protection, vol. 44, no. 1, pp. 28-31, 2017.

[3] M. Xie, Z. X. Liu, and J. Mao, "Analysis on influence of different factors to contact stiffness of support and roof in roadway," Journal of Safety Science and Technology, vol. 12, no. 10, pp. 102-106, 2016.

[4] S. Z. Li, L. Zhu, A. H. Sun, C. Xie, and Q. Yan, "Mechanical analysis of support structure based on over-under-excavated tunnels," Journal of China Coal Society, vol. 42, no. 11, pp. 2817-2825, 2017.

[5] M. Dolipski, P. Cheluszka, and P. Sobota, "Investigating the simulated control of the rotational speed of roadheader cutting heads, relating to the reduction of energy consumption during the cutting process," Journal of Mining Science, vol. 51, no. 2, pp. 298-308, 2015.

[6] A. Ebrahimabadi, K. Goshtasbi, K. Shahriar, and M. C. Seifabad, "A model to predict the performance of roadheaders based on the rock mass brittleness index," Journal of the Southern African Institute of Mining and Metallurgy, vol. 111, no. 5, pp. 355-364, 2011.

[7] O. Acaroglu and C. Erdogan, "Stability analysis of roadheaders with mini-disc," Tunnelling and Underground Space Technology, vol. 68, pp. 187-195, 2017.

[8] S. B. Wang, F. Gao, R. Li et al., "Auto-cutting and shaping control system of arbitrary roadway section based on PCC," Journal of China Coal Society, vol. 38, no. S1, pp. 261-266, 2013.

[9] R. Ling, Research on High-Order Sliding Mode Control of Cantilever Tunneling Robot, Chongqing University, Chongqing, China, 2009.

[10] Z. X. Liu, M. Xie, C. X. Xie, and J. Lu, "Analysis on dynamic response of cutting unit of excavation-supporting-bolting combined machine in drilling process," Technical Bulletin, vol. 55, no. 20, pp. 267-275, 2017.

[11] R. Shirani Faradonbeh, A. Salimi, M. Monjezi, A. Ebrahimabadi, and C. Moormann, "Roadheader performance prediction using genetic programming (GP) and gene expression programming (GEP) techniques," Environmental Earth Sciences, vol. 76, no. 16, p. 584, 2017.

[12] H. Ergin and O. Acaroglu, "The effect of machine design parameters on the stability of a roadheader," Tunnelling and Underground Space Technology, vol. 22, no. 1, pp. 80-89, 2007.

[13] E. M. Eyyuboglu and N. Bolukbasi, "Effects of circumferential pick spacing on boom type roadheader cutting head performance," Tunnelling and Underground Space Technology, vol. 20, no. 5, pp. 418-425, 2005.

[14] O. Acaroglu and H. Ergin, "A new method to evaluate roadheader operational stability," Tunnelling and Underground Space Technology, vol. 21, no. 2, pp. 172-179, 2006.

[15] Z. X. Liu, M. Xie, C. X. Xie, and M. Xie, "Effect of delay characteristics of cutting mechanism on forming accuracy of roadway section," Journal of China Coal Society, vol. 45, no. 3 , pp. 1195-1202, 2020.

[16] J. L. Li and Z. S. Lian, "Research on variable structure force control of working device of cantilever roadheader," Coal Science and Technology, vol. 39, no. 12, pp. 88-91, 2011. 